\title{
Analysis of Influence of Profits on Employees and Enterprises based on the Reform of the Concept of Human Resource Management of SMEs
}

\author{
Yuchen Zhang ${ }^{1}$, Ze Tian $^{2}$ \\ ${ }^{1)}$ Business School, Hohai University, Nanjing, Jiangsu, China \\ ${ }^{2)}$ Institute of Southern Jiangsu Economic Development, Hohai University, Changzhou, Jiangsu, China
}

\begin{abstract}
Due to the particularity of the industry that the information enterprises stay in, it is more important in the talents than other industries. How to optimize the staff management, the reform of concept on human resource management is necessary. But there exists a lot of information enterprises that fall behind in their human resource management, which lead to high staff mobility. How to retain talents requires more attention from the enterprises. The article based on the game theory to analyze the influence of profits on employees and enterprises on the reform of the concept of human resource management of information enterprises, and then put forward some matters needing attention on the reform process to provide guidance for the long-term development of information enterprises.
\end{abstract}

Key words - game theory, SMEs, reform of concept, analysis of profit

\section{博栾视角下中小型企业人力资源观念转变对其收益的 影响分析 \\ 张雨辰 ${ }^{1}$, 田泽 ${ }^{2}$ \\ 1) 河海大学商学院, 南京, 江苏 \\ 2) 河海大学苏南经济研究所, 常州, 江苏}

\begin{abstract}
摘 要 中小型企业由于其所处行业的特殊性, 人才的重要性较其他性质企业更为突出。中小型企业如何优化其对于员工的管理, 需要企业从对人力资源管理的观念上进行转变。但在现实中不乏由于人力资源管理观念落后, 而导致中小型企业人力资源流动率较高。 如何留住人才成为了这类企业需要重视和关注问题。本文通过博弯视角, 旨在分析我国中小型企业人力资源管理观念的转变对于企业 和员工的收益影响, 并在分析的基础上, 提出中小型企业在实现人力资源管理观念转变的过程中应注意的问题, 从而为企业的长远发 展提供指导意义。
\end{abstract}

关键词 博亦，中小型企业，观念转变，收益分析

\section{1. 引言}

不同以往，随着国人对人力资源管理概念认识的深化, 在我国中小型企业中, 有不少企业已经意识到人才的重要 性, 并对人力资源管理愈发重视。但基于现实, 一方面, 面对实力强劲, 管理体系较为成熟的大型企业, 中小型企

河海大学中央高校科研业务费项目资助（资助号：2013B19414 和 2013B30614)
业在人才留用方面仍存在着明显的劣势。另一方面, 很多 员工将中小型企业视为自己职业生涯中的一个跳板，仅仅 是将这些企业作为自己积累工作经验的平台, 相较于在中 小型企业继续工作, 大多数员工通常会选择进入让自身收 益更大的企业。很多员工选择跳槽, 是因为他们认为相较 于当前的企业, 未来可能进入的企业在人力资源管理的各 个方面都更能与其需求相契合。而中小型企业人员的频繁 
流失与更迭, 使得企业难以充分发挥人才优势以获得稳定 且长远的发展。企业在人力资源管理观念方面的转变对于 企业自身以及其员工而言, 都存在着不同程度的收益, 如 何使得企业与员工双方获得最满意的结果, 企业在人力资 源管理观念上的转变对于员工的选择以及双方收益的影响 又是怎样的, 本文通过建立起中小型企业与员工的博亦模 型, 通过分析, 来得出最优的选择。

本文在此探讨的有关企业人力资源观念的转变不仅仅 在于企业高层在管理人的过程中思想上的转变, 还包括在 工作环境和工作流程方面的管理人员的行为转变, 设备调 整和资金配置的变动。因此, 企业在人力资源管理观念上 的转变所带来的变动, 相较于原先企业的各个方面, 会是 十分显著和巨大的, 在此, 本文更倾向于将这种转变定义 为是对企业的一种变革, 为了表述简洁, 在进行博亦分析 时, 下文将这种人力资源管理观念的转变称之为变革。

在此, 本文更倾向于将这种转变定义为是对企业的一 种变革, 为了表述简洁, 在进行博亦分析时, 下文将这种 人力资源管理观念的转变称之为变革。

\section{2. 模型的假设条件和参数涵义}

\section{1 假设条件}

（1）博亦的决策主体为中小型企业和员工。博弯双方目标 都是为了获取收益最大化。企业的选择是变革与不变 革, 员工的选择是跳槽和不跳槽。

（2）中小型企业在此所实行的变革, 指的是企业有变革意 向或变革意向已确定但尚在进行中, 变革结果目前只 能被预估。员工和企业具有长远视角, 在双方进行抉 择的过程中, 双方以自身的未来收益为参考的。

（3）中小型企业在人力资源管理方面的变革会花费企业一 定的成本, 员工会因此而受到额外的收益, 并且员工 会有在工作积极性上的提升, 并对企业也会带来收益 上的增值。

（4）员工在获得进入新企业的机会之时, 会以自己未来的 收益为参考, 并且只有在新企业能为员工带来高于当 前企业收益的情况下, 员工才会选择跳槽。企业员工 流失在此模型中不考虑对新员工招聘, 培训等花费的 成本。

\section{2 参数涵义}

$\mathrm{P}_{1}$ : 中小型企业为员工支付的薪酬; $\mathrm{P}_{2}$ : 大型企业为 员工支付的薪酬

$\mathrm{C}_{1}$ ：员工为中小型企业付出的成本; $\mathrm{C}_{2}$ ：员工为大型 企业付出的成本
$\mathrm{F}$ ：员工对中小型企业的贡献

$\mathrm{R}$ ：中小型企业变革所花费的成本, 例如: 企业为员 工工作环境的提升, 薪资福利的增加以及满足员工需求所 作出的努力。

$\mathrm{P}_{\mathrm{H}}$ : 变革后企业给员工带来的增值收益, 例如: 企业 改革使得企业更能关注员工的需求, 为员工带来心理上的 满足和物质上的丰富。 $\mathrm{P}_{\mathrm{H}}$ 的性质与 $\mathrm{P}_{\mathrm{C}}$ 相似, 主要取决于变 革的性质, 成功的变革带来较大 $\mathrm{P}_{\mathrm{H}}$, 失败的变革使得 $\mathrm{P}_{\mathrm{H}}$ 为零或负值。

$\mathrm{P}_{\mathrm{C}}$ : 变革后员工为企业带来的增值收益, 例如: 员工 在企业变革后工作积极性的提升所带来的工作效率的提 高, 工作态度的改善等。但变革分有效的变革和无效的变 革, 判断变革成效的标准在于 $\mathrm{R}$ 与 $\mathrm{P}_{\mathrm{C}}$ 之间的关系以及 $\mathrm{P}_{\mathrm{H}}$ 的大小。

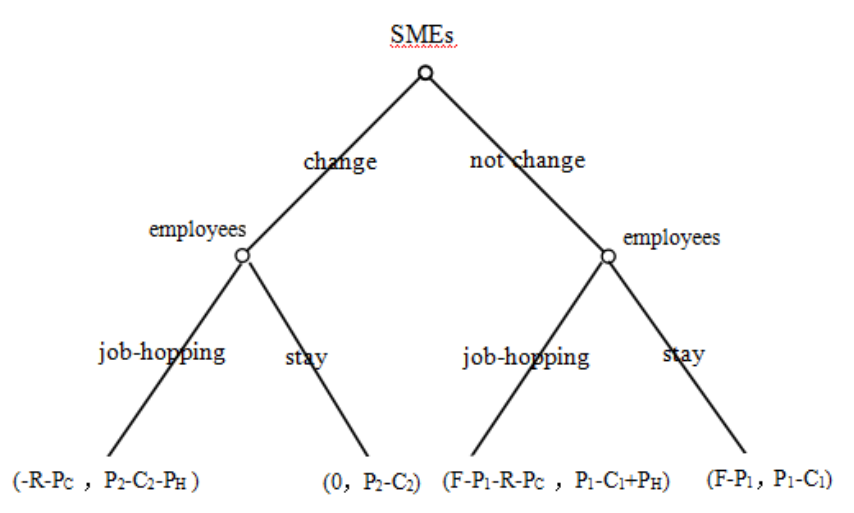

图 2.1 博亦决策树模型

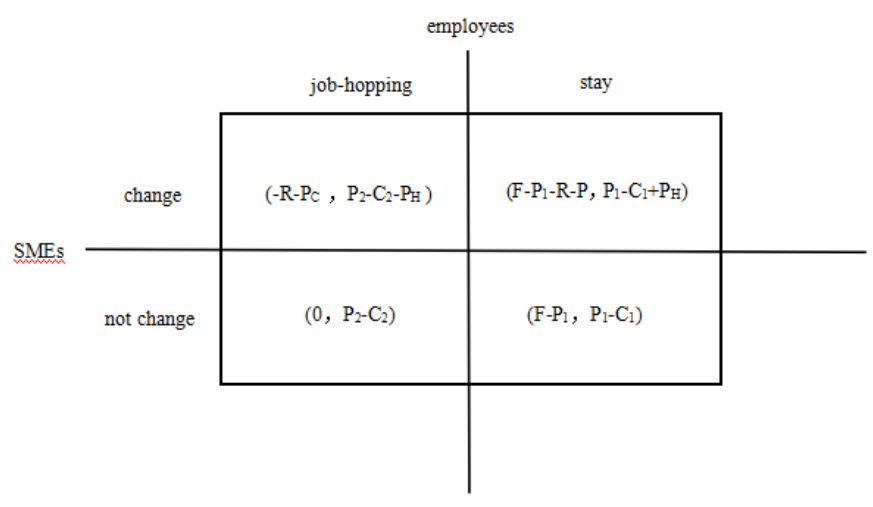

图 2.2 博亦决策矩阵

\section{3. 模型分析}

在上述博亦矩阵中, 可以看到当员工获得了可以进入 大型企业工作的机会, 并且其所能收获的新收益大于当前 收益, 员工必然会选择跳槽, 企业要想要留住员工, 必须 要使得员工当前收益超过进入大型企业所能获得的收益, 
这就需要考虑企业变革能给员工带来的收益增值是否可以 留住员工。而企业变革必然会花费一定成本, 所以在员工 选择跳槽时, 企业更倾向于选择不进行变革, 从而降低成 本, 但这又必将会导致员工无法长期留存于企业, 使得企 业无法充分利用人才, 为企业培养最适宜的人才。

本文在此进行的博弯讨论是在中小型企业有改革倾 向, 员工能接收到企业的改革意向并能预估到改革在未来 能给其带来的利益, 并且员工有着随时跳槽的可能性。本 文假设员工跳槽的几率为 $\mathrm{a}$, 不跳槽的几率为 $1-\mathrm{a}$ 。企业能 进行成功变革的几率为 $b$, 变革无法实现的几率为 $1-b$ 。则 可以分两种情况来讨论此博亦模型:

第一种情况是: 给定 $b$, 则员工跳槽（ $a=1 ）$ 和不跳槽 $(a=0)$ 的期望收益分别为:

$$
\begin{aligned}
& E_{P}(b, 1)=\left(P_{2}-C_{2}-P_{H}\right) b+\left(P_{2}-C_{2}\right)(1-b) ; \\
& E_{P}(b, 0)=\left(P_{1}-C_{1}+P_{H}\right) b+\left(P_{1}-C_{1}\right)(1-b) 。 \\
& \text { 解 } E_{P}(b, 1)=E_{P}(b, 0)
\end{aligned}
$$

得 $\mathrm{b}^{*}=\left(\mathrm{P}_{2}-\mathrm{C}_{2}\right)-\left(\mathrm{P}_{1}-\mathrm{C}_{1}\right) / 2 \mathrm{P}_{\mathrm{H}}-\left(\mathrm{C}_{2}-\mathrm{C}_{1}\right)$, 如果企业变革概率 小于 $b^{*}$, 则员工的选择是跳槽; 如果企业变革概率大于 $b^{*}$, 则员工的选择为不跳槽。

第二种情况是: 给定 $a$, 则企业变革 $(b=1)$ 和不变革 $(b=0)$ 的期望收益分别为:

$$
\begin{aligned}
& \mathrm{E}_{\mathrm{P}}(1, \mathrm{a})=\left(-\mathrm{R}-\mathrm{P}_{\mathrm{C}}\right) \mathrm{a}+\left(\mathrm{F}-\mathrm{P}_{1}-\mathrm{R}+\mathrm{P}_{\mathrm{C}}\right)(1-\mathrm{a}) \\
& \mathrm{E}_{\mathrm{P}}(0, \mathrm{a})=0 * \mathrm{a}+\left(\mathrm{F}-\mathrm{P}_{1}\right)(1-\mathrm{a}) 。
\end{aligned}
$$

解 $E_{P}(1, a)=E_{P}(0, a)$, 得 $a^{*}=\left(P_{C} R\right) P{ }_{C}$, 若员工跳槽 概率大于 $a^{*}$, 则企业的选择为不变革; 若员工跳槽概率小 于 $a^{*}$, 则企业的选择为变革。

上述的分析, 反映的是企业和员工双方的行为意向, 从现实角度而言, 这两者会由于环境的变动而做出不同的 抉择。

(1) 由于 $-R-P_{C}<0$, 当 $P_{2}-C_{2}>P_{1}-C_{1}$, 即员工在大型企 业的收益大于当前收益时, 员工会选择跳槽的情况下, 而企业会选择不变革。当 $\mathrm{P}_{2}-\mathrm{C}_{2}<\mathrm{P}_{1}-\mathrm{C}_{1}$ 时, 说明员工 认为新企业不能提供高于其当前收益的收益, 所以会 选择不跳槽, 但从长远角度而言, 一旦员工在新企业 所能获得收益高于当前企业, 员工还是会选择跳槽。 所以, 企业不进行变革的最终结果是员工跳槽。

（2）当 $\mathrm{P}_{\mathrm{C}}>\mathrm{R}$, 且 $\quad+{ }_{1}>{ }_{1} \& \mathrm{P}_{2} \mathbb{E}_{\mathrm{H}}$, 即 $\mathrm{P}_{\mathrm{H}}>\left[\left(\mathrm{P}_{2}-\mathrm{C}_{2}\right)-\left(\mathrm{P}_{1} 1_{1}\right] /\right.$, 说明了企业的变革是有效 的, 成功的, 变革使得员工带给企业的增值收益大于 企业变革所花费的成本, 并且员工在当前且的收益大 于在新企业的收益, 故在此条件下, 企业选择变革,
员工选择不跳槽。从长远角度而言, 这对双方都是最 优的选择。但变革的有效性不仅仅是要看 $\mathrm{P}_{\mathrm{C}}$ 与 $\mathrm{R}$ 之间 的关系, 还应考虑 $\mathrm{P}_{\mathrm{H}}$, 即变革为员工带来的增值收益, 若 $\mathrm{P}_{\mathrm{H}}<\left[\left(\mathrm{P}_{2}-\mathrm{C}_{2}\right)-\left(\mathrm{P}_{1}-\mathrm{C}_{1}\right)\right] / 2$, 则员工会选择跳槽, 企 业变革的结果则是带来损。

(3) 当 $\mathrm{P}_{\mathrm{C}}<\mathrm{R}$, 说明了企业的变革不是有效的, 变革所花 费的成本超过了变革后员工带给企业的增值收益, 因 此, 企业在此条件下会选择不变革, 而当员工遇到能 够提供其高于当前收益的企业时, 员工则会选择跳槽, 故从长远意义上考虑, 低效的变革最终无法使得企业 留住, 难以实现对人才的充分利用。

\section{4. 结论与对策}

通过对上述博弯模型的分析, 可以得知, 企业和员工 为了获得自身利益最大化, 双方都会以对方的决策为参考, 结合现实情境来做出判断, 但由于变革是一种观念, 一种 过程, 其结果存在有多重可能性, 并且员工随时存在着跳 槽的可能性, 因此, 这是一种动态的博亦。但从现实角度 和长远意义而言, 此博弯的均衡为 (变革, 不跳槽), 即企 业进行变革 (有效的变革), 员工继续留在企业。为此, 为 了能让企业的变革使得企业和员工双方获得最大收益, 结 合上述分析, 本文得出了一些今后中小型企业在进行变革 时所需注意的问题。

变革并不意味着一旦实施必会成功, 中小型企业应注 重提升变革的有效性。从对上述博弯模型的分析可以看出 判断变革有效与否的三个关键指标- - $\mathrm{R}, \mathrm{P}_{\mathrm{C}}$ 和 $\mathrm{P}_{\mathrm{H}}$ 。 因此, 中小型企业在进行变革时应注意控制变革成本, 尽可能提 高变革所带给员工的增值收益以及变革后员工带给企业的 增值收益。

（1）要降低企业的变革成本, 最主要的就是企业变革要抓 住核心, 企业要明白变革的目的是为了满足员工的需 求, 只有满足了员工的需求, 使得员工工作积极性得 以提升, 激发了员工参与工作的热情和创造性, 才能 算是达到了变革的目的。譬如企业注重对员工工作环 境的改善, 但如若仅仅是工作硬件上的提升, 但员工 间矛盾重重, 不能融洽相处, 员工的工作积极性和专 注性依旧不会有较大的提升, 这种程度的变革不能称 之为有效的变革。并且, 作为在企业进行人力资源观 念转变过程中的主力军, 企业相关从事人力资源管理 工作的人员素质也亟需提高, 包括要掌握如何与员工 有效交流, 在员工和企业间正确地传达各自的观点, 以及对于行业内一些前沿的管理方法的关注。

(2) 随着 80 后, 尤其是 90 后这批在职场中的新秀军的不 断壮大, 企业高层对这批员工的管理的重点也应有所 
改变。相关调查统计显示, 现今的 8090 后员工更注重 的是企业对其心理需求的满足, 诸如他们在选择企业 时看中的是企业能否为其提供职业生涯发展的明确规 划, 弹性的工作时间以及能够能获得参与到企业决策 的机会等等。而企业对于这种心理需求的满足, 无论 是对员工还是企业而言, 双方所能获得的收益往往是 巨大的, 甚至可以说是无穷的。

(3) 中小型期企业在进行变革的过程中, 需要员工的配合。 在企业进行变革的过程中, 由于原先固有的一些习惯 的存在, 很多变革的效果往往需要在变革后一两年才 能较明显的体现出来, 比如员工参与企业决策, 这种 参与途径, 参与程度以及参与效果是需要经过反复的 实践, 评估与完善的。因此, 员工也应站在长远角度 去考察和思考企业变革在未来能为其带来的收益。但 现实中往往很多员工更加注重于眼前的利益, 使得企 业在变革伊始或变革效果不显著时, 失去一些能力较
强的员工, 但企业也应站在长远角度来思考, 企业的 变革以及越来越成熟的体制运行, 将会吸引更多优秀 的员工, 但前提是企业的变革一定是有效且动态的, 能够不断的完善且符合员工和社会的需求。

\section{参考文献(References)}

[1] Wenbo Hu and Jinfeng Liu. "Game analysis of human resource recruitment channels," China Market, no.1, pp.27-29, 2012.

[2] Xiaojing Jia, Shaosen Zhou, Renan Jia, "The game analysis of enterprise recruitment activities," Statistics and Decision, no.1, pp.21-23, 2006.

[3] Guoqing Yao, Game Theory, Peking: Higher Education Press, 2007.

[4] Chenggang Wei, "Human resource management current situation and optimization analysis of SMEs," Modern Business, no.27, pp.184, 2011. 